\title{
Consumer Perception of E-Service QuAlity: \\ From Internet Purchaser and Non-Purchaser PERspectives
}

\author{
Dr. Zhilin Yang \\ City University of Hong Kong \\ Kowloon, Hong Kong
Dr. Minjoon Jun
Las Cruces, NM \\ New Mexico State University
}

\begin{abstract}
This exploratory study expands the knowledge concerning service quality dimensions in the context of Internet commerce, from the differing perspectives of two groups: Internet purchasers and Internet non-purchasers. Six primary service quality dimensions perceived by Internet purchasers were uncovered: reliability, access, ease of use, personalization, security, and credibility while seven dimensions were discovered for Internet non-purchasers: security, responsiveness, ease of use, reliability, availability, personalization, and access. When examining the relative importance of each dimension affecting overall service quality assessment, the "reliability" factor was found to be the most important dimension for Internet purchasers while Internet non-purchasers consider "security" as their most critical concern.
\end{abstract}

The Internet commerce industry has gone through an initial period of focusing on new customers to the present stage of both retaining and attracting customers. Instant price comparisons on the Web, brought by powerful search engines, make non-price competitive advantages, such as service quality, ever more critical in retaining and attracting customers (Griff \& Palmer 1999; Jarvenpaa \& Todd 1997; Liu \& Arnett 2000). What brings online customers back, primarily, is a sense of loyalty that comes from an Internet company! offering better service than anyone else (Hoff, McWilliams \& Saveri 1998).

To offer better services, it is necessary for Internet companies to investigate what existing and potential customers expect for service quality. In the context of Internet commerce, existing customers are those who have utilized the Internet as a channel to purchase products and services. Potential customers, for

\footnotetext{
'For this study, the term "Internet-only company" means that a company conducts business solely through the internet without any physical stores or branches. The term "hybrid company" refers a company which has physical stores or branches with the transactional Web sites options. The term "Internet company", also called "online company", is defined as a company which has transactional Web sites. It can be either Internet-only or hybrid companies.
} 
Internet commerce industry as a whole, are generally those who have utilized the Internet as a source to search for information about desired products and services but have never purchased through the Internet (i.e., they prefer to purchase through traditional channels). For purposes of this study, these two types of consumers are coined "Internet purchasers" and "Internet non-purchasers", respectively.

The ideal action for Internet companies is to improve and maintain all service quality attributes that satisfy both existing and potential customers' needs and wants. However, given that both large and small online companies have limited resources, priorities must be set among alternative service attributes in making investment decisions based on a company's business strategies. If online companies can understand the similarities and differences of key service quality dimensions perceived by Internet purchasers and Internet non-purchasers, different service offering strategies can be applied to retain existing Internet customers and attract potential customers. Therefore, it is necessary to understand both Internet purchasers' and non-purchasers' perceptions of service quality attributes related to Internet purchasing.

Nevertheless, no empirical attention has been given to examining the service quality attributes in the context of Internet commerce from the perspectives of Internet purchasers and Internet non-purchasers. This article, therefore, intends to expand the body of knowledge relating to the service quality construct within the Internet commerce context. Three specific research questions are investigated:

- What are the key underlying dimensions of service quality within the framework of Internet commerce as perceived by Internet purchasers and nonpurchasers?

- Are there any differences between the two groups' perceptions of service quality dimensions? If any, what are they?

- Which service quality attributes most significantly impact the overall service quality as assessed by Internet purchasers and non-purchasers?

\section{Conceptual Background}

\section{Internet Purchasers Versus Internet Non-Purchasers}

Internet purchasers and non-purchasers are somewhat interchangeable. An Internet non-purchaser tends to be an Internet purchaser if $s /$ he feels purchasing through the Internet is the best option. Meanwhile, an Internet purchaser can be 'transformed' into an Internet non-purchaser after unhappy or even painful experiences. For instance, many online consumers were adversely impacted due to poor order fulfillment and delivery (Gray 2000; Jedd 2000). Consequently, they may keep searching for information through the Internet but may stop online purchasing. As Mittal and Katrichis (2000) argued, the service quality attributes important to new customers might not be the ones that are important 
to loyal customers; the same rule may apply to Internet purchasers' and Internet non-purchasers' different perceptions of service quality dimensions.

With competition only a click away, Internet companies strive to retain their customers and are struggling to convert their Web site visitors to online purchasers. Although hybrid companies (traditional companies with a transactional Web site option) can influence Internet non-purchasers to visit their stores physically, they still would like their customers to complete purchasing transactions through their Web sites to ensure that orders are placed. Therefore, for both Internet-only companies and hybrid companies, the key issues are: (1) how to retain these relatively disloyal Internet purchasers; and (2) how to turn Internet non-purchasers into Internet purchasers.

\section{Perceived Service Quality Dimensions}

Perceived service quality can be defined as "a global judgment or attitude relating to the superiority of a service." (Parasuraman, Zeithaml \& Berry 1988) Over the past three decades, researchers have attempted to discover the global or standard attributes of a service that are important to the customer and that contribute significantly to customers' quality assessment. Sasser, Olsen, and Wyckoff (1978) reported seven major attributes in the context of the service industry: security, consistency, attitude, completeness, conditions, availability, and training. Later, ten dimensions were revealed in an exploratory study conducted by Parasuraman, Zeithaml \& Berry (1985); tangibles, reliability, responsiveness, communication, credibility, security, competence, courtesy, understanding the customer, and access. Based on these ten dimensions, Parasuraman et al. (1988) further purified and distilled these ten dimensions of service quality to five: tangibles, reliability, responsibility, assurance, and empathy. These five service quality attributes constitute the basis for global measurement of service quality, namely, SERVQUAL.

Since that time, SERVQUAL has been applied to various service industries, although it has received some criticism (for a comprehensive review, see Cronin and Taylor 1994; Dabholkar, Thorpe \& Rentz 1996). The primary concerns raised by many scholars are that: (1) there is difficulty in measuring different types of expectations (Cronin \& Taylor 1994) and (2) service quality dimensions tend to be context-bounded and service-type-dependent (Bienstock 1997; Van Dyke, Kappelman \& Prybutok 1997). Alternatively, Cronin and Taylor (1994) have argued that perceived service performance (SERVPERF) would be a better indicator of service quality.

During the past several years, a number of conceptual and empirical studies have attempted to address key attributes of service quality directly or indirectly related to Internet Commerce. Rice (1997) examined what made users revisit a Web site and discovered that the most important variables are design features, such as content, layout, ease of finding information, navigability, and emotional experience, such as enjoyable visits. Hoffman and Novak (1997) pointed out 
that personalization is the essence by which Internet firms valorize the Internet as a unique consumer market.

When investigating the Web sites of the top 100 U.S. retailers, Griffith and Krampf (1998) mentioned that the lack of prompt responsiveness, especially to email inquires, was the most common phenomenon in cyberspace. They pointed out that customer service access through the Web sites needed enough staff support to satisfy their customers. Balfour, Farquhar, and Langmann (1998) put emphasis on transaction security and personal information privacy when examining consumer needs in global electronics. Dellaert and Kahn (1999) conducted four computerbased experiments to understand how waiting time of information download negatively affects consumers' perception of the performance of the Web site.

Liu and Arnett (2000) identified information quality, system use, system design quality, and playfulness as four major determinants for the success of Web sites in the context of Internet commerce. Based on the survey of 250 online banking and securities brokerage users, Sohn (2000) found that trust, interactiveness, ease of use, content/functionality of Web sites, reliability, and speed of delivery were the six significantly important service quality dimensions perceived by customers. Kaynama (2000) assesses the service quality of online travel agencies in terms of attributes such as content, access, navigation, design, response, background, and personalization and customization

The aforementioned service attributes, however, were discovered either within a narrowly defined domain or on the basis of Internet purchaser perspective only. No empirical study has been conducted to date to systematically and extensively uncover the underlying key dimensions of service quality in the Internet commerce setting, at least not from the perspectives of both Internet purchasers and non-purchasers.

\section{Relative Importance of Service Quality Attributes}

Not all service quality dimensions have the same effect on consumers' perceptions of service quality. The key is to find, among various service quality attributes, which dimensions are more crucial to enhancing the level of service quality, and to what degree they do so. In this manner, an organization can understand what service areas should be emphasized to most effectively improve quality while avoiding investing valuable resources in providing service quality attributes that may not pay off (Oliva, Oliver \& MacMillan 1992).

In examining the relative importance of service quality attributes to the overall service quality as perceived by customers, a number of researchers adopted SERVQUAL in various service industries. For example, Rosen and Karwan (1994) identified the significant attributes in four different service industries, such as: "understanding the customer" for restaurants, "assurance" and "reliability" for health care, "reliability" and "tangibles" for lecture teaching, and "assurance" for bookstores. Johnston (1995) identified "responsiveness" as an important factor at the industrial level. 
In the context of Internet commerce, few studies have addressed the relatively important attributes in determining consumers' perception of overall service quality. Though Sohn (2000) uncovered six service quality dimensions perceived by online financial service customers, the author did not further investigate which attributes were most important for customers to evaluate overall service quality.

This study attempts to fill the gap by addressing the following research question: what are the most influential online service quality attributes to achieve high levels of overall service quality perceived by Internet purchasers and nonpurchasers?

\section{Methodology}

The debate between the SERVQUAL and SERVPERF scales has been focused on whether expectation should be used and how it should be measured. Although expectations do play a vital role in traditional perceived service quality, personal interviews with online customers in this study revealed that most of the participants did not have a clear conception of what expectations they held for online service. This viewpoint is consistent with the results of six in-depth focus group discussions with online consumers conducted by Zeithaml, Parasuraman, and Malhotra (2001). They state: "unlike focus group participants who articulated with ease the nature and the source of their expectations for traditional SQ (Parasuraman, Zeithaml \& Berry 1985; Zeithaml, Berry \& Parasuraman 1993), participants in our study often seemed at a loss to articulate their e-SQ expectation when it came to issues of order fulfillment" (p. 15). The main underlying reason is that the Internet as a new information technology device is still a relatively new service channel. Even highly experienced customer groups encounter difficulty in shaping definitive pre-consumption expectations (Zeithaml, Parasuraman \& Malhotra 2001). From this perspective, perceived performance of service attributes has been widely used in measuring information system quality (Dabholkar, Thorpe \& Rentz 1996).

Additionally, even though certain expectations do exist for some online customers, there have been few research efforts that provide conclusive evidence in choosing appropriate types of expectations in the setting of Internet commerce. Given that (1) perceived performance measurement methods have been shown to be highly effective in measuring technology-based services and (2) difficulty existed in measuring online customer expectations, this study utilized customer perceived performance, instead of both expectation and perceived performance, as the determinant of service quality. In other words, customer perceived performance is suitable for measuring service quality.

Measures. In this study, Internet purchasers are defined as those who purchased at least one product or service through the Internet during the last 12 months. Internet non-purchasers refer to those who have utilized the Internet to 
search for information on products and services, but who have not actually purchased through the Internet during the last 12 months. A semi-structured interview questionnaire was developed based on an extensive review of service quality and Internet commerce literatures. To further understand consumers' perception of Internet purchasing service quality, face-to-face personal interviews were conducted with four customers. These four persons were selected from participants in an e-commerce program and voluntarily attended the interviews. Two of them were experienced Internet purchasers. The other two had surfed the Internet for more than three years, but had not purchased any items on the Internet during the last 12 months. One of them did buy several items approximately two years ago and subsequently ceased Internet shopping. Each interview lasted from 15 minutes to one hour.

The two experienced Internet purchasers were asked to think about their most recent purchase experience on the Internet. The author prompted them to discuss several key questions, including: (1) what aspects of their purchasing led to their positive or negative experiences; (2) what specific criteria did they use in assessing the service quality provided by the Web site; (3) what did they expect from Internet companies and where did these expectations originate; and (4) what did they like most/least about Internet purchasing. The interviewee who ceased Internet purchasing explained her bad purchasing experiences and the main reasons she had stopped shopping online. The other non-purchaser discussed major obstacles that had prevented him from using the Internet as a transactional channel. Both of them were encouraged to elaborate on their perceptions of the weaknesses of Internet purchasing. They also commented on what kind of service quality improvements should be made in order to attract them to online purchasing.

Besides literature review and personal interviews, we also adapted and modified several dimensions of SERVQUAL proposed by Parasuraman, Zeithaml and Berry (1985), such as reliability, responsiveness, and access, to fit the setting of Internet commerce. As a result, fifty items of service quality for Internet purchasers, and forty-eight items for Internet non-purchasers were initially developed. Three academicians who have research interests in e-commerce were asked to review all 98 items to examine if each item reflected the dimension it was designed to measure. Based on their suggestions, 13 scale items were further deleted and 10 were reworded. Thus, the pretest questionnaire had a total of 41 items of perceived service quality for Internet purchasers and 44 for Internet non-purchasers. Next, nine students participating in a doctoral seminar course were asked to take a pretest survey. As a result of their written comments, several ambiguous scale items in the survey questionnaire were further reworded.

The finalized survey questionnaire consisted of three parts. Part I included 41 items concerning consumers' experiences and perceptions of online purchases and the overall perceived service quality measure. Part II contained 43 items on 
Internet non-purchasers' experiences or perceptions of information searching, and the overall perceived service quality measure. Part III consisted of general information about respondents' backgrounds. The respondents were requested to assess each of the scale items in regard to perceived service quality. A Likerttype six point scale was used for each statement, where $1=$ strongly disagree, 2 $=$ disagree, $3=$ neutral, $4=$ agree, $5=$ strongly agree, and $6=$ not available.

Data Collection. The sampling frame for the data set consisted of a list of 1600 subscribers to a regional Internet Service Provider (ISP) company in an area located in the Southwestern United States. Questionnaires were mailed to 950 subjects randomly selected from the mail list of 1600 ISP subscribers. At the beginning of the questionnaire, three screening questions were asked to identify which group subjects belonged to (1) Internet purchasers, (2) Internet nonpurchasers, (3) Others such as those who have used the Internet as a personal communication means only (i.e. checking personal e-mail), but not for any activities related to product and service purchasing and information searching within the last 12 months. Then, Internet purchasers were asked to complete Parts I and III based on their most recent experience with Internet purchase of a product or service. Internet non-purchasers were asked to complete Parts II and III in terms of their decision of not choosing the Internet as a channel to purchase a product/service after an information search. Respondents who only selected "Others" were not required to complete the survey questionnaire.

After 10 days of the initial mail-out, two follow-up e-mail messages were sent to remind targeted subjects at weekly intervals. Only 13 questionnaires were returned as undeliverable. Of the 285 returned questionnaires, three were unusable due to incomplete information, while ten respondents claimed that they were "Others". As a result, the effective number of questionnaires was 271 with a response rate of $28.5 \%$. Since the focus of this study was on Internet purchasers and Internet non-purchasers' different perceptions of online service quality dimensions, their personal user and demographic profiles were omitted.

\section{Analysis and Findings}

\section{Identifying Key Service Quality Dimensions}

Because of the exploratory nature of this study, a principal component factor analysis was utilized to identify key underlying service quality dimensions. The highly recommended Varimax rotation with Kaiser normalization was used (Nunnally and Bernstein 1994). Missing values were replaced by means.

After deleting two scale items with low inter-item correlations in the purchaser group, the initial analysis extracted ten factors that were evident on the scree plot and had eigenvalues greater than 1 . Items that were cross-loading were further eliminated. After four iterations, eighteen additional items were deleted. The retained 21 items were factor analyzed again. Six factors emerged and accounted for $67.4 \%$ of the total explained variance (see Table 1). The 
reliability of each factor was estimated by computing its Cronbach Alpha, which was $0.89,0.78,0.81,0.73,0.77$, and 0.59 , respectively.

Using a similar process for the Internet non-purchaser group, seven dimensions were generated and accounted for $69.83 \%$ of the total explained variance. The reliability of each factor was estimated by computing its Cronbach Alpha, which was $0.89,0.88,0.81,0.68,0.80,0.74$, and 0.78 , respectively. For both groups, each item represented an independent attempt to measure a particular construct. All items within a given scale were strongly loaded on one factor and weakly on all the other factors, thereby satisfying the requirements of convergent and discriminant validity of a constructs. Additionally, these factors had relatively high reliability and were deemed appropriate for further analyses.

As shown in Table 1, the six factors identified with the Internet purchaser group were reliability, access, ease of use, personalization, security, and credibility. Four items were related to attributes of "reliability", namely: the correctness of order fulfillment, prompt delivery, accurate billing, and reply to customers' inquiries within a promised time frame. The "access" factor included four items: (1) the list of company's street and e-mail addresses, phone and fax numbers; (2) accessibility of service representatives; and (3) availability of chat rooms, bulletin boards, and other communication channels. As a unique dimension in the context of Internet commerce, "ease of use" related to items like: ease-of-remembering URL address, well-organized/structured and easy-to-follow catalogs, and concise and understandable contents, and terms and conditions. The "personalization" attribute consisted of such items as individualized attention and personal thank you notes from online retailers, and availability of a message area for customer questions and comments. The "security" factor included security for providing personal information, and online purchase risk. Finally, the "credibility" factor referred to the business history of online retailers and special rewards or discounts offerings.

The seven dimensions identified in the Internet non-purchaser group, as shown in Table 2, embrace security, responsiveness, ease of use, availability, reliability, personalization, and access. The security dimension included high risk associated with online purchase, continuous credit card charges, sensitive information, and distrustful Internet retailers. The "responsiveness" dimension included slow Internet speed, online jam, slow responses from online retailers, slow information retrieval, and delayed responses. The "ease of use" attribute was related to difficulties in following the organization and structure of online catalogs, understanding content, grasping terms and conditions related to products and services, and the lack of sufficient product/service description. The "availability" dimension referred to limited product and service selection, hardto-find desired products and services, and out-of-date information contained in online catalogues. The "reliability" attribute was related to failure to e-mail or call customer by a promised time, uncertainty of delivering the right products, and worry concerning incorrect charges. The "personalization" dimension re- 
Table 1

Factor Analysis Results on Perceived Service Quality for Internet Purchasers

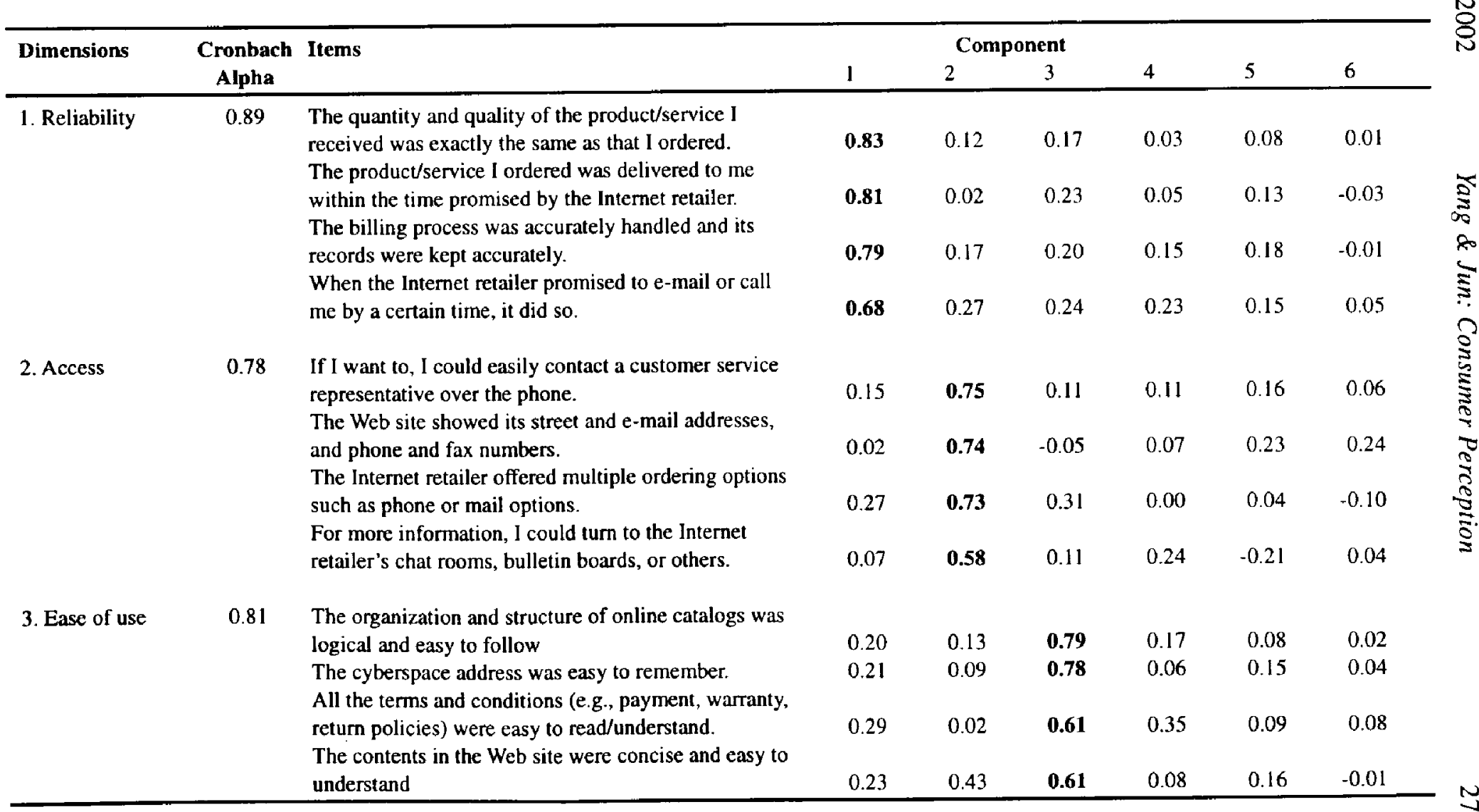


Table 1 continued

Factor Analysis Results on Perceived Service Quality for Internet Purchasers

\begin{tabular}{|c|c|c|c|c|c|c|c|c|}
\hline \multirow[t]{2}{*}{ Dimensions } & \multirow{2}{*}{$\begin{array}{l}\text { Cronbach } \\
\text { Alpha }\end{array}$} & \multirow[t]{2}{*}{ Items } & \multicolumn{5}{|c|}{ Component } & \multirow[b]{2}{*}{6} \\
\hline & & & 1 & 2 & 3 & 4 & 5 & \\
\hline \multirow[t]{3}{*}{ 4. Personalization } & 0.73 & $\begin{array}{l}\text { The Internet retailer gave me a personalized or } \\
\text { individualized attention. } \\
\text { The Web site had a message area for customer }\end{array}$ & 0.06 & 0.12 & 0.07 & $\mathbf{0 . 8 4}$ & 0.21 & 0.07 \\
\hline & & $\begin{array}{l}\text { questions and comments. } \\
\text { I received a personal "thank you" note via e-mail }\end{array}$ & 0.04 & 0.32 & 0.21 & 0.64 & 0.13 & -0.09 \\
\hline & & or other media after I placed an order. & 0.25 & 0.00 & 0.19 & 0.62 & -0.01 & 0.24 \\
\hline \multirow[t]{2}{*}{ 5. Security } & 0.77 & $\begin{array}{l}\text { I felt secure in providing sensitive information } \\
\text { (e.g., credit card number) for online purchase. } \\
\text { I felt the risk associated with online purchase }\end{array}$ & 0.17 & 0.07 & 0.22 & 0.19 & 0.80 & 0.08 \\
\hline & & was low. & 0.23 & 0.12 & 0.13 & 0.11 & 0.79 & 0.05 \\
\hline \multirow[t]{3}{*}{ 6. Credibility } & 0.59 & $\begin{array}{l}\text { The Web site showed how long the Internet } \\
\text { retailer has been in this online business. } \\
\text { I received special rewards and discounts from }\end{array}$ & -0.18 & 0.28 & 0.11 & -0.06 & 0.00 & 0.80 \\
\hline & & doing businesses with the Internet retailer. & 0.15 & -0.05 & -0.02 & 0.23 & 0.12 & 0.76 \\
\hline & & $\begin{array}{l}\text { Percentage of Variance Explained by } \\
\text { Each Dimension (total } 67.40 \% \text { ) }\end{array}$ & 15.55 & 13.27 & 12.80 & 10.06 & 8.48 & 7.24 \\
\hline
\end{tabular}

Notes a. Extraction Method: Principal Component Analysis. b. Rotation Method: Varimax with Kaiser Normalization. c. Rotation Converged in 7 Iterations. 
Table 2

Factor Analysis Results on Perceived Service Quality for Internet Non-Purchasers

\begin{tabular}{|c|c|c|c|c|c|c|c|c|c|}
\hline \multirow[t]{2}{*}{ Dimensions } & \multirow{2}{*}{$\begin{array}{c}\text { Cronbach } \\
\text { Alpha }\end{array}$} & \multirow[t]{2}{*}{ Items } & \multicolumn{6}{|c|}{ Component } & \multirow[b]{2}{*}{7} \\
\hline & & & 1 & 2 & 3 & 4 & 5 & 6 & \\
\hline \multirow[t]{6}{*}{ I. Security } & \multirow[t]{6}{*}{0.89} & I felt the risk associated with online purchase was high. & 0.83 & 0.18 & 0.12 & 0.26 & 0.00 & 0.04 & -0.02 \\
\hline & & charge my credit card, even after I cancel an order. & 0.79 & 0.27 & 0.06 & 0.02 & 0.02 & 0.01 & 0.10 \\
\hline & & $\begin{array}{l}\text { The security issue of sensitive information was a } \\
\text { major obstacle to my online purchase. }\end{array}$ & 0.79 & 0.04 & -0.16 & 0.09 & 0.10 & -0.02 & 0.30 \\
\hline & & I felt insecure in providing sensitive information & & & & & & & \\
\hline & & (e.g., credit card number) for online purchase. & 0.78 & 0.05 & -0.01 & 0.09 & -0.06 & 0.19 & -0.15 \\
\hline & & I couldn't trust the Intemet retailer. & 0.61 & 0.26 & 0.12 & 0.21 & 0.09 & 0.04 & 0.17 \\
\hline \multirow[t]{6}{*}{ 2. Responsiveness } & \multirow[t]{6}{*}{0.88} & $\begin{array}{l}\text { The Internet speed was too slow particularly at the } \\
\text { peak time of its usage. }\end{array}$ & 0.26 & 0.83 & 0.17 & 0.04 & 0.09 & 0.14 & 0.05 \\
\hline & & $\begin{array}{l}\text { I often encountered online jam in searching for } \\
\text { product/service information. }\end{array}$ & 024 & 0.77 & 001 & 0.20 & -0.10 & 0.08 & 0.05 \\
\hline & & I often felt frustrated about slow response time in & & & & & & & \\
\hline & & using online stores. & 0.27 & 0.72 & 0.07 & 0.09 & 0.12 & 0.27 & 0.13 \\
\hline & & $\begin{array}{l}\text { The system of the Web site didn't rapidly retrieve } \\
\text { the information I requested. }\end{array}$ & 0.09 & 0.68 & 0.30 & 0.29 & 0.23 & -0.02 & 0.26 \\
\hline & & $\begin{array}{l}\text { The Internet retailer didn't respond to my inquiry } \\
\text { promptly. }\end{array}$ & -0.02 & 0.57 & 0.04 & 0.06 & 0.12 & 0.39 & 0.32 \\
\hline
\end{tabular}


Table 2 continued

Factor Analysis Results on Perceived Service Quality for Internet Non-Purchasers

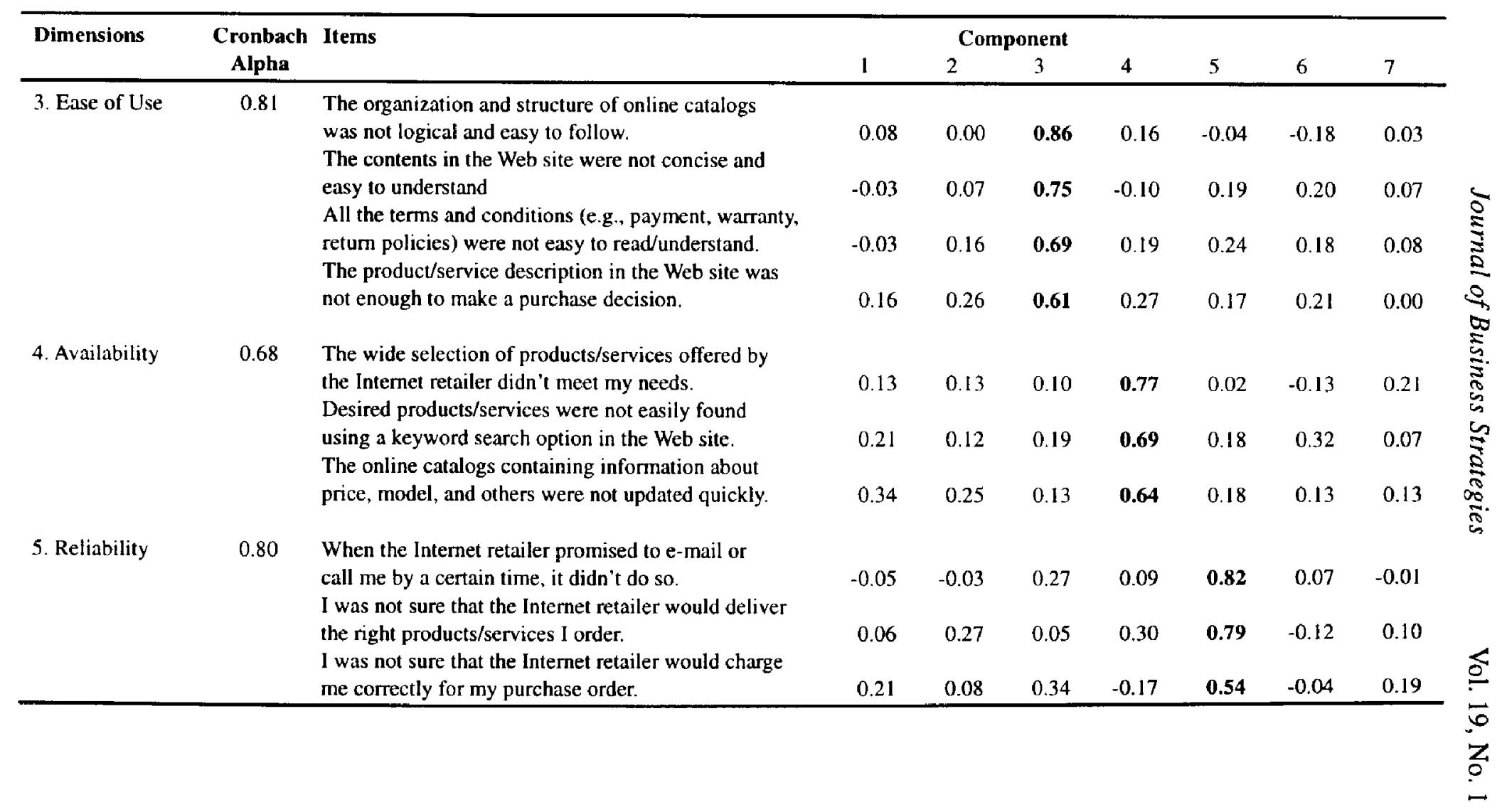




\section{Table 2 continued \\ Factor Analysis Results on Perceived Service Quality for Internet Non-Purchasers}

\begin{tabular}{|c|c|c|c|c|c|c|c|c|c|}
\hline \multirow[t]{2}{*}{ Dimensions } & \multirow{2}{*}{$\begin{array}{l}\text { Cronbach } \\
\text { Alpha }\end{array}$} & \multirow{2}{*}{ Items } & \multicolumn{6}{|c|}{ Component } & \multirow[b]{2}{*}{7} \\
\hline & & & 1 & 2 & 3 & 4 & 5 & 6 & \\
\hline \multirow[t]{2}{*}{ 6. Personalization } & 0.74 & $\begin{array}{l}\text { It was difficult to receive personalized customer } \\
\text { service from an Intemet retailer. } \\
\text { It was not easy to interact with Internet retailers }\end{array}$ & 0.12 & 0.23 & -0.01 & 0.03 & -0.16 & 0.80 & 0.10 \\
\hline & & real-time for their product/service questions. & 0.08 & 0.18 & 0.28 & 0.09 & 0.10 & 0.77 & 0.10 \\
\hline \multirow[t]{6}{*}{ 7. Access } & 0.78 & $\begin{array}{l}\text { I couldn't easily contact a customer service } \\
\text { representative over the phone. }\end{array}$ & 0.26 & 0.20 & 0.21 & 0.01 & -0.16 & 0.02 & 0.73 \\
\hline & & $\begin{array}{l}\text { It was not easy to access the Internet retailer since } \\
\text { it had no toll free phone number, street address in } \\
\text { the Web site. }\end{array}$ & 0.01 & 0.09 & -0.05 & 0.24 & 0.27 & 0.09 & 0.71 \\
\hline & & For more information, I couldn't easily turn to the & & & & & & & \\
\hline & & Internet retailer's chat rooms, bulletin boards, etc. & 0.05 & 0.20 & 0.05 & 0.30 & 0.06 & 0.30 & 0.54 \\
\hline & & Percentage of Variance Explained by & & & & & & & \\
\hline & & Each Dimension (total $69.83 \%$ ) & 14.44 & 12.87 & 10.77 & 8.65 & 8.17 & 7.70 & 7.24 \\
\hline
\end{tabular}

Notes a. Extraction Method: Principal Component Analysis. b. Rotation method: Varimax with Kaiser Normalization. c. Rotation Converged in 8 Iterations. 
ferred to the difficulty in receiving personalized customer service and interacting with Internet retailers in real time for questions. Lastly, the "access" attribute embraced inaccessibility of retailers, customer representatives, and online help sources such as chat rooms and bulletin boards.

\section{Examining the Relative Importance of Service Quality Dimensions}

Two regression analyses were used to examine the relative importance of the various dimensions of perceived service quality, along with three demographic variables: age, gender, and education levels, affecting overall perceived service quality for both Internet purchasers and Internet non-purchasers, respectively:

$$
\begin{gathered}
\mathrm{SQ}_{\mathrm{P}}=\beta_{0}+\beta_{1} \mathrm{FAC} 1+\beta_{2} \mathrm{FAC} 2+\beta_{3} \mathrm{FAC} 3+\beta_{4} \mathrm{FAC} 4+\beta_{5} \beta \mathrm{FAC} 5+\beta_{6} \mathrm{FAC} 6+ \\
\beta_{7} \text { Age }+\beta_{8} \mathrm{Edu}+\beta_{9} \text { Gender }+\varepsilon \\
\mathrm{SQ}_{\mathrm{NP}}=\gamma_{0}+\gamma_{1} \mathrm{facl}+\gamma_{2} \mathrm{fac} 2+\gamma_{3} \mathrm{Fac} 3+\gamma_{4} \mathrm{fac} 4+\gamma_{5} \mathrm{fac} 5+\gamma_{6} \mathrm{fac} 6+\gamma_{7} \mathrm{fac} 7+ \\
\gamma_{8} \mathrm{Age}+\gamma_{9} \mathrm{Edu}+\gamma_{10} \text { Gender }+\varepsilon
\end{gathered}
$$

Where: $\mathrm{FAC1}=$ Reliability; $\mathrm{FAC} 2=$ Access; $\mathrm{FAC} 3=$ Ease of use; FAC 4 = Personalization; FAC5 = Credibility; FAC6 = Security; fac1 $=$ Security; fac2 = Responsiveness; fac3 = Ease of Use; fac4 $=$ Availability; fac5 = Reliability; fac $6=$ Personalization; fac7=Access; Edu =Education Levels; $\mathrm{SQ}_{\mathrm{p}}=$ Internet Purchasers' Perceived Overall Service Quality; $\mathrm{SQ}_{\mathrm{np}}=$ Internet non-purchasers' Perceived Overall Service Quality; and $\beta_{\mathrm{i}}$ and $\gamma_{\mathrm{i}}$ represent the parameters to be estimated.

Pursuant to the initial regression run, we examined the standardized residual in oeder to identify and delete outliers, but none were found. The mean of all scale item ratings within a given factor was utilized to form measures of the independent variables. The overall perceived service quality for two groups was entered as two dependent variables. The stepwise method was used to run the linear regression. When the regression analysis was repeated with $70 \%, 80 \%$, and $90 \%$ randomly selected cases from the total sample for both groups, the parameter estimates were stable. This finding, along with the clean factor loadings of explanatory variables, suggests that multicollinearity is unlikely to affect interpretation of the findings.

Table 3 demonstrates the results of the regression analysis. The coefficients of determination $\left(R^{2}\right)$ of the Internet purchaser and Internet non-purchaser equations were $80.1 \%$, and $77.0 \%$, respectively, while the $F$ values of both equations were 43.14 and 20.05 (significant at 0.000 level). Therefore, the regression equations achieved a satisfactory level of goodness of fit in predicting the variance of both Internet purchasers' and Internet non-purchasers' perceived overall service quality in relation to respective service quality dimensions and three demographic variables. 
As far as the relative importance of the service quality dimensions is concerned, the reliability factor carried the heaviest weight for Internet purchaser's perceived service quality, followed by personalization, ease of use, and access. Two factors, security and credibility, along with three demographical variables, namely age, gender, education level, appear not to be statistically significant in affecting either consumers' perceived survey quality or overall satisfaction. For Internet non-purchasers, the most significantly important factor in affecting their perceptions of online service quality was found to be security, followed by personalization and access. Dimensions such as responsiveness, ease of use, availability, and reliability do not significantly impact overall service quality assessment.

\section{Discussion}

The following section will elaborate on derived service quality dimensions for both Internet purchasers and Internet non-purchasers, and on the relative importance of these dimensions affecting overall service quality assessment.

\section{Derived Perceived Service Quality Dimensions}

Six underlying service quality attributes perceived by Internet Purchasers were identified: reliability, access, ease of use, personalization, credibility, and security. Seven dimensions were uncovered for the Internet non-purchasers: security, responsiveness, ease of use, availability, reliability, personalization, and access. Upon close examination of these factors, it can be inferred that the two groups share much common ground, considering that the dimensions of reliability, personalization, security, and access are important attributes. As predicted, there still exist several different attributes perceived by the two groups. Except for the slightly different content for each similar dimension, two dimensions, availability and responsiveness, are unique to Internet non-purchasers.

It is interesting to compare traditional service quality dimensions to those of Internet-based service quality. Most traditional service quality dimensions proposed by Parasuraman, Zeithaml, and Berry (1985), such as reliability, access and customization, are also demanded by online customers. The newly identified factors, such as ease of use and security, are Internet-based related. While some dimensions contain many traditional service quality aspects, they do have some unique characteristics related to the Internet commerce setting. A more detailed discussion of each dimension follows.

Reliability. Both Internet purchasers and Internet non-purchasers require online companies having the ability to perform the promised service accurately and in a timely manner. They expect to be billed and charged correctly. Of equal importance is order delivery. The quality of delivery should include promptness and ensure that both correct and intact products and services are delivered, in 
Table 3

\section{A. Regression Analysis Results Between Internet Purchasers' Perceived Service Quality and Service Quality Dimensions'}

\begin{tabular}{lccc}
\hline Independent Variables & $\begin{array}{c}\text { Standardized } \\
\text { Coefficients Beta }\end{array}$ & t-value & p-value $^{2}$ \\
\hline Reliability & 0.563 & 5.495 & $0.000^{* * *}$ \\
Personalization & 0.530 & 5.886 & $0.000^{* * *}$ \\
Ease of Use & 0.246 & 2.255 & $0.014^{*}$ \\
Access & 0.199 & 2.568 & $0.029^{*}$ \\
Security & 0.069 & 0.809 & 0.423 \\
Credibility & 0.034 & 0.457 & 0.650 \\
Age & 0.078 & 0.971 & 0.337 \\
Gender & 0.078 & 1.115 & 0.271 \\
Education Level & -0.048 & -0.668 & 0.508 \\
\hline
\end{tabular}

Note: 1. Dependent Variable: Internet Consumers' Perceived Overall Service Quality $(F=43.143$, d.f. $=4$, Significant $=0.000, R$ Square $=0.801$, Adjusted $R$ Square $=0.782$,

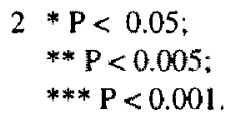

\section{B. Regression Analysis Results Between Internet Non-Purchasers' Overall Perceived Service Quality and Service Quality Dimensions ${ }^{1}$}

\begin{tabular}{lccc}
\hline Independent Variables & $\begin{array}{c}\text { Standardized } \\
\text { Coefficients Beta }\end{array}$ & t-value & p-value ${ }^{2}$ \\
\hline Security & 0.564 & 4.058 & $0.001^{* *}$ \\
Personalization & 0.295 & 2.605 & $0.018^{*}$ \\
Access & 0.338 & 2.435 & $0.026^{*}$ \\
Responsibility & 0.082 & 0.052 & 0.607 \\
Ease of use & 0.042 & 0.331 & 0.745 \\
Availability & 0.032 & 0.210 & 0.836 \\
Reliability & 0.053 & 0.444 & 0.663 \\
Age & 0.146 & 1.187 & 0.251 \\
Gender & 0.067 & 0.538 & 0.598 \\
Education Level & -0.017 & -0.125 & 0.902 \\
\hline
\end{tabular}

Note: $\quad$ a. Dependent Variable: Intemet Non-Purchasers' Perceived Overall Service Quality. $(F=20.048$, d.f. $=3$, Significant $=0.000$, R Square $=0.770$, Adjusted $R$ Square $=0.731)$

$$
\text { b. } \begin{array}{rl}
* P & <0.05 \\
& * * \\
* & P 0.005
\end{array}
$$


ordered quantities, at times convenient to customers. Consumers will not tolerate goods arriving late or damaged, being misplaced, or having the wrong product shipped to them in error. Consumers also prefer to have increasing access to information about the progress of their order.

In reality, product and service fulfillment still remains a big challenge for online suppliers and most online consumers feel frustrated with the poor service reliability provided by virtual stores (Jedd 2000 ). The primary reasons reside in the lack of strong internal and external collaboration. Internal collaboration includes tight integration of Web sites with customer service operations and communication among different functional departments. External collaboration means integration of supply chain partners (i.e., suppliers, packaging and shipping companies). Irrespective of the operational models of warehousing and shipping, what counts, as the most important factor, is the quality of the management system (Gray 2000). For instance, replenishment systems should have the capacity to forecast demand for particular items and order them in time. Some measures, dealing particularly with packaged connectors to third-party systems (such as ERP and Customer Relationship Management (CRM) applications, and formal partnerships with vendors of third-party software) can be taken to implement effective backend integration.

Responsiveness. Consumers expect Internet retailers to respond to their in * quiries promptly. Prompt responses help consumers resolve their problems and make decisions in a timely fashion. However, compared with physical stores, Internet retailers often lack real-time interaction with customers. For instance, e-mail is a very common means for online consumers to communicate with retailers; but a recent study shows that $42 \%$ of the top-ranked Web sites took longer than five days to respond to a customer's e-mail inquiry, never responded, or were not accessible by e-mail (Wilcox 1999).

Other unique aspects concerning the responsiveness dimension include information retrieval speed and Internet speed. Internet consumers want to find desired information quickly and accurately. Studies have revealed that there is a significant positive correlation between information download speed and Web user satisfaction (Hoffman \& Novak 1996). The negative effects of siow information download can be attenuated by providing the consumer with notice of download duration time wherever download waiting occurs and by reducing unexpected waiting occasions and times to a minimum (Dellaert \& Kahn 1999). Further, to increase the navigation speed, Internet retailers should choose an efficient host server and avoid using extensive high-resolution graphics (Doherty, Ellis-Chadwick \& Hart 1999).

Access. Both Internet purchasers and Internet non-purchasers have a desire to access various sources provided by Internet companies for help. Consumers expect that a site will have a street and an e-mail address, plus a toll free phone and fax numbers available for them to contact customer representatives easily 
(Burke 1997). In addition, online consumers favor multiple order channels, such as phone and mail order. Finally, accessing help from other consumers is very important in the sense that consumers tend to acquire knowledge from each other. Therefore, providing both traditional and online communication channels such as chat rooms and bulletin boards is a necessity (Berthon, Pitt \& Watson 1996).

Ease of Use. Ease of use is a prominent factor in determining customers' decision to adopt a new information technology (Davis 1989). Thus, Web-based stores should make it easy for customers to proceed through the whole purchasing process by minimizing technical difficulties.

More specifically, an easy-to-remember cyberspace name is important for online consumers to revisit or locate a firm since the Internet has grown to include a tremendous number of competitors. Both groups - purchasers and searchers - grant priority to on-screen information concerning products and services. Since the Web site functions as an information system, the organization and structure of online catalogues should be easy to follow and navigate. Most importantly, contents of the Web site should be concise and easy to understand. All terms and conditions concerned with products and services should be easy to read and comprehend. As Rice (1997) concluded, for Internet-based shopping to achieve mass-market penetration, it must be made substantially easier for consumers to navigate and locate information or content.

Personalization. Consumers long for personalized or individualized attention and expect to receive a personal "thank you" note as confirmation after they place an order. A message area in which consumers may ask questions and post comments is also a necessity. The lack of real-time interaction tends to prevent potential customers from purchasing through the Internet. Only by managing all forms of interaction - Web hits, e-mails, phone-and fax-based contacts - in a single framework, can Internet companies shift their staffing and service priorities as customer preferences change. In other words, it is critical for businesses to engage customers in personalized dialogue and to learn more about their needs to better anticipate their future preferences.

Certain techniques such as a "rules engine" that can drive personalization based on information from the database, are critical to satisfy individual customers. In addition, to show a human face to customers, Internet companies may add personal support to staff telephones, answer e-mail, and train customers in the use of the Internet medium.

Credibility. Consumers are well aware of the history of online retailers and whether they receive special rewards and discounts offered is an important index for evaluating the credibility of online retailers. Given the intensive competitive business environment, the history of an online business is a good indicator of its prospects. Providing special rewards and discounts for consumers as promised often demonstrates that the firm possesses basic integrity and credibility in relation to its customers. 
Security. Both Internet purchasers and Internet non-purchasers appear to be worried about the risk associated with online purchase, especially with respect to secure credit card transactions and privacy of sensitive information. For Internet non-purchasers, trustfulness of Internet retailers is also a concern.

The perceived lack of security on public networks is definitely a stumbling block (Balfour, Farquhar \& Langmann 1998). Personal information such as credit card numbers transmitted to vendors from consumers can be coded and decoded by other people using Encryption algorithms. Additionally, consumers often want to retain some level of privacy or anonymity for their activities. A Web server, however, can track the identity of the user's computer through "cookies", a text file placed on a user's hard drive. Online shoppers are concerned about Web sites that don't provide clear and prominent statements about privacy and security matters. These disadvantages facing consumers require Internet vendors to be very responsible for both consumer transaction activities and personal information.

Availability. This identified dimension is unique to Internet non-purchasers. Availability refers to a limited range of products and services, failure to find desired items and/or updated information regarding them. Customers often look for products and services unavailable in their local stores. Limited selection of products and services or outdated information is most likely to keep Internet non-purchasers from purchasing online. In a survey of 220 consumers from Austin, Texas, Jarvenpaa and Todd (1997) uncovered that the main impediments to consumer acceptance of Internet shopping were difficult-to-find specialty items, and limitation of the offerings of individual sites.

\section{Importance of Service Quality Dimensions}

The regression results show that both personalization and access factors are considered significantly important to service quality perceived by both groups. In reality, increasing the level of accessibility requires sufficient staff support, which adds more costs to the Internet firm. In order to be personalized, Internet commerce needs effective techniques such as pull and push personalization skills (Luedi 1997), and requires installation of a CRM system. Thus, achieving an adequate trade-off of self-service against personalization is an art-form, in the sense that Internet companies can maintain a high level of customer satisfaction while keeping costs in a minimum.

It is interesting to note the different perceptions of both groups related to the most important factor in determining overall service quality. Internet purchasers consider the reliability attribute to be the foremost critical factor for achieving high levels of service quality; this is consistent with other traditional service quality studies (Bitner, Booms \& Tetreault 1990; Parasuraman, Zeithaml \& Berry 1988). Online consumers also regard ease of use as a significant factor that affects overall service quality assessment. In contrast to the prevailing viewpoint, online security and privacy are not significant factors in determining 
service quality perceived by online purchasers. However, Internet non-purchasers did put the security attribute in the most important position. Risks involving Internet purchasing and the truthfulness of Internet companies are, indeed, the major reasons preventing mere Internet non-purchasers from becoming Internet purchasers.

\section{Conclusions and Limitations}

Focusing on service quality has been a priority and one of the primary concerns in Internet commerce (Griffith \& Krampf 1998). This study reveals that, to better understand consumers' assessment of online service quality, it is beneficial to investigate the key underlying dimensions perceived by both Internet purchasers and Internet non-purchasers. Internet companies should focus on such service quality dimensions as reliability, personalization, ease of use, and access; these are desired by both Internet purchasers and Internet non-purchasers, and their focus should be customized to specific requirements. While credibility is solely related to Internet purchasers, availability is the unique dimension related to Internet non-purchasers.

Based on their different business strategies, Internet companies can devote valuable corporate resources to the important service quality attributes uncovered by this study. For instance, improvement of the level of personalization and access constitutes a necessity for both retaining and attracting customers, since these factors significantly affect overall service quality assessment. To retain existing customers, the first priorities are high service reliability and prompt responsiveness. Furthermore, Internet companies have to take measures to help potential Internet customers such as Internet non-purchasers overcome their foremost concerns: security and trust.

Caution should be taken when generalizing the findings of this study. A methodological concern is the sample from a regional ISP provider. Due to geographical limitations, participants may possess certain attributes that differ from those in other parts of the United States. Future research may use more diversified random samples to verify the dimensions developed in this study. The generalization of online service quality dimensions also requires numerous studies crossing different online industries including financial services, health care and other online services. Further, based on this pilot study, formal hypotheses about online consumers' perceived service quality and overall satisfaction can be established, tested, verified or modified, in future studies, through more rigorous methodologies such as the structural equation model. 


\section{References}

Balfour, A., Farquhar B., \& Langmann G. (1998). The consumer needs in global electronic commerce. Electronic Markets, 8 (2), 9-12.

Berthon, P., Pitt L., \& Watson R. (1996). Marketing communication and the World Wide Web. Business Horizons, 39 (September-October), 24-32.

Bienstock, C. C. (1997). Measuring physical distribution service quality. Journal of the Academy of Marketing Science, 25 (1), 31-44.

Bitner, M. J., Booms, B. H., \& Tetreault M. S. (1990). The service encounter: Diagnosing favorable and unfavorable. Journal of Marketing, 54 (January), 71-84.

Burke, R. R. (1997). Do you see what I see? The future of virtual shopping. Journal of Academic of Marketing Science. 25 (4), 352-360.

Cronin, J.J. \& Taylor, S.A. (1994). SERVPERF versus SERVQUAL: Reconciling performance-based and perceptions-minus-expectations measurement of service quality. Journal of Marketing, 58 (January), 125-131.

Dabholkar, P.A., Thorpe, D.I. \& Rentz, J. O. (1996). A measure of service quality for retailing stores: scale development and validation. Journal of the Academy of Marketing Science, 24 (1), 3-16.

Davis, F. D. (1989). Perceived usefulness, perceived ease of use, and user acceptance of information technology. MIS Quarterly. 13, 318-340.

Dellaert, B. G. \& Kahn, B. E. (1999). How tolerable is delay?: Consumers' evaluations of Internet Web sites after waiting. Journal of Interactive Marketing, 13 (1), 41-54.

Doherty, N. F., Ellis-Chadwick, F., \& Hart, C. A. (1999). Cyber retailing in the UK: The potential of the Internet as a retail channel. International Journal of Retail and Distribution Management, 27 (1), 22-36.

Gray, R. (2000). E-tail must deliver on Web promises. Marketing March 2, 37-38.

Griff, D. A. \& Palmer, J. (1999). Leveraging the Web for corporate success. Business Horizons, 39 (January-February), 3-10.

Griffith, D.A. \& Krampf, R. A. (1998). An examination of the Web-based strategies of the top 100 U.S. retailers. Journal of Marketing Theory and Practice, 6 (3), 12-23.

Hoff, R. C., McWilliams G., \& Saveri, G. (1998). The 'click here' economy. Business Week, June (22). 
Hoffman, D. L. \& Novak, T. P. (1996). Marketing in hypermedia computer-mediated environments: conceptual foundations. Journal of Marketing. 60 (July), 50-68.

Hoffman, D. L. \& Novak, T. P. (1997). A new paradigm for electronic commerce. The Information Society, 13, 43-54.

Jarvenpaa, S. L. \& Todd, P. A. (1997). Is there a future for retailing on the Internet?. In Peterson, R. A. (ed.) Electronic Marketing and the Consumer. Thousand Oaks.

Jedd, M. (2000). Fulfillment: A crucial E-business challenge. Logistics Management and Distribution Report, April, E25-E26.

Johnston, R. (1995). The determinants of service quality: satisfier and dissatisfiers. International Journal of Service Industry Management. 8 (5), 53-71.

Kaynama, S. A (2000). A proposal to assess the service quality of online travel agencies: An exploratory study. Journal of Professional Services Marketing. 21 (1), 63-88.

Liu, C. \& Arnett, K. P. (2000). Exploring the factors associated with Web site success in the context of electronic commerce. Information \& Management. 38 (October), 2334.

Luedi, Ariel F. (1997). Personalize or perish. Electronic Markets. 7 (3), 22-25.

Mittal, V. \& Katrichis, J. M. (2000). Distinctions between new and loyal customers. Marketing Research, 12 (1), 26-32.

Nunnally \& Bernstein (1994). Psychometric theory. (3rd Ed.) New York: McGraw-Hill.

Oliva, T. A., Oliver, R. L., \& MacMillan, I. C. (1992). A catastrophe model for developing service satisfaction strategies. Journal of Marketing. 56 (July), 83-95.

Parasuraman, A., Zeithaml, V. A., \& Berry, L. L. (1985). A conceptual model of service quality and its implications for future research. Journal of Marketing. 49 (5), 41-50.

Parasuraman, A., Zeithaml, V. A., \& Berry, L. L. (1988). SERVQUAL: A multiple-item scale for measuring consumer perceptions of service quality. Journal of Retailing. 64 (1), 12-40.

Rice, M. (1997). What makes users revisit a Web site. Marketing News, 31 (6), 12-13.

Rosen, L. D. \& Karwan, K. R. (1994). Prioritizing the dimensions of service quality: An empirical investigation and strategic assessment. International Journal of Service Industry Management, 5 (4), 39-52.

Sasser, W. E., Olsen R. P., \& Wyckoff, D. D. (1978). Management of service operations: Text and cases. Boston: Allyn \& Bacon. 
Sohn, C. S. (2000). Customer evaluation of Internet-based service quality and intention to re-use internet-based services. Unpublished dissertation, Southern Hlinois University, IL: Carbondale.

Van Dyke, T.P., Kappelman, L.A. \& Prybutok, V.R. (1997). Measuring information systems service quality: Concerns on the use of the SERVQUAL questionnaire. MIS Quarterly, 21 (June), 195-208.

Wilcox, N. (1999). The months ahead. Kiplinger's Personal Finance Magazine (January), $19-20$.

Zeithaml, V. A., Berry, L. L., \& Parasuraman, A. (1993). The nature and determinants of customer expectations of service. Journal of the Academy of Marketing Science. 21 (1) $1-12$.

Zeithaml, V. A., Parasuraman, A., \& Malhotra, A. (2001), A conceptual framework for understanding e-service quality: Implications for future research and managerial practice. Working paper, Cambridge, MA: Marketing Science Institute.

Dr. Zhilin Yang is an Assistant Professor of Marketing at City University of Hong Kong. This manuscript was completed when he was a doctoral student at New Mexico State University. His research interests include Internet-based services marketing, customer relationship management, international marketing, and supply chain management. He has published in International Marketing

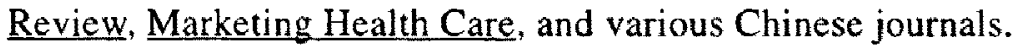

Dr. Minjoon Jun is an Associate Professor in the Management Department at New Mexico State University. He holds a Ph.D. in Operations Management from the Georgia State University. His research interests include total quality management, service operation management, supply chain management, and operations strategy. 
